\title{
The Ras family of GTPases in cancer cell invasion
}

\author{
R. Hernández-Alcoceba ${ }^{a}$, L. del Peso ${ }^{b}$ and J. C. Lacal ${ }^{\mathrm{c}, *}$ \\ ${ }^{a}$ Department of Internal Medicine and Comprehensive Cancer Center, The University of Michigan Medical \\ School, Ann Arbor (Michigan 48109, USA) \\ bepartment of Pathology and Comprehensive Cancer Center, The University of Michigan Medical School, \\ Ann Arbor (Michigan 48109, USA) \\ 'Instituto de Investigaciones Biomédicas, c/Arturo Duperier, 4., E-28029 Madrid (Spain), Fax + 3491585 4606, \\ e-mail: jclacal@iib.uam.es
}

\begin{abstract}
The ability of tumoral cells to invade surrounding tissues is a prerequisite for metastasis. This is the most life-threatening event of tumor progression, and so research is intensely focused on elucidating the mechanisms responsible for invasion and metastasis. The Ras superfamily of GTPases comprises several subfamilies of small GTP-binding proteins whose functions include the control of proliferation, differentiation, and apoptosis, as well as cytoskeleton organization. The
\end{abstract}

development of metastasis is a multistep process that requires coordinated activation of proliferation, motility, changes in normal cell-to-cell and cell-to-substrate contacts, degradation of extracellular matrix, inhibition of apoptosis, and adaptation to an inappropriate tissue environment. Several members of the Ras superfamily of proteins have been implicated in these processes. The present review summarizes the current knowledge in this field.

Key words. Ras; Rho; metastasis; invasion; cytoskeleton; adhesion; apoptosis.

\section{Introduction}

Metastasis is the most common and serious, life-threatening complication of cancer. At the time of cancer diagnosis, almost $50 \%$ of the patients have already developed metastasis [1]. The discovery of oncogenes (mutated forms of normal cellular genes involved in growth control) identified the genetic basis of cancer. Many intracellular pathways that control cell growth are now known, and alterations in these normal routes are key events in the generation of tumors. In contrast, the molecular mechanisms responsible for the acquisition of metastatic ability are poorly understood.

The most important oncogene in humans is ras, which has been implicated in up to $30 \%$ of all cancers. The ras genes were first found as the transforming sequence in murine acute transforming retrovirus and in experiments aimed to isolate transforming genes derived from human tumoral DNA [2]. The Ras superfamily of proteins is a large group of small molecular-mass

\footnotetext{
* Corresponding author
}

proteins belonging to the larger group of GTP-binding proteins or G proteins [3, 4]. All these proteins share the ability to bind guanine nucleotides and are able to hydrolyze GTP. They function as molecular switches, and can be found in two different states, GDP or GTP bound. These small GTPases have a higher affinity for GDP than for GTP, so in resting conditions they bind GDP. After delivery of the appropriate signal, specific exchange factors interact with them promoting the release of GDP and the binding of GTP. This presumably induces a conformational change in the small GTPases that enables them to interact with their targets. When the GTP is hydrolyzed by the intrinsic GTPase activity, the cycle is completed and the small GTPase returns to its resting, GDP-bound conformation [4]. The endogenous GTPase activity is enhanced by interaction with specific catalytic factors termed GTPase activating proteins (GAPs).

The distinct members of the Ras superfamily are involved in a wide diversity of cellular functions, the Ras and Rho groups being of special interest because they are implicated in the development and progression of 
malignancies. The Ras proteins are key components of the signal transduction pathways triggered by a large number of different extracellular signals, including mitogens [4]. Ras proteins are targeted to the plasma membrane by specific posttransductional modifications in their carboxyl-terminal region [5] and this cellular localization is critical for their function [6]. The mechanism of Ras protein activation by extracellular signals has been studied in detail for growth factors such as epidermal growth factor (EGF) [7]. After activation of the appropriate membrane receptor by its agonist, Sos, an exchange factor for Ras proteins, is recruited to the receptor tyrosine kinase with the aid of adapter molecules such as Grb2 [8]. The translocation of Sos from cytoplasm to the receptor at the plasma membrane brings it close to Ras proteins, facilitating their interaction and consequent activation [9, 10]. In their GTP-bound conformation, Ras proteins can interact with several molecules resulting in their activation. Among Ras targets, the serine/threonine kinase Raf [11-13], Ral-GDS [14, 15], and the phosphatidyl inositol 3-kinase (PI3K) [16] are the best characterized. Raf is the first step in a cascade of cytosolic kinases, known as the mitogen-activated protein kinase (MAPK) cascade, which leads to the phosphorylation of several intracellular substrates including transcription factors [17]. PI3K can be activated by Ras proteins or by direct interaction with receptor tyrosine kinases. Upon activation, it phosphorylates phosphatidyl inositol at position 3 of the inositol ring. The resulting lipids are second messengers that mediate the activation of various molecules including the small GTP-binding protein Rac, certain Ser/Thr kinases of the protein kinase C (PKC) family and the Ser/Thr kinase Akt/PKB [18]. Ral-GDS regulates another group of small GTPases of this superfamily, Ral, which may directly control phospholipase D [18] with the subsequent generation of important lipid-derived second messengers such as phosphatidic acid (PA) and diacylglycerol (DAG) [19].

The Rho family of proteins includes several members: Rho A, Rho B, Rho C, Rho D, Rho E, Rho G, TC10, Rac1A, Rac1B, Rac2, CDC42Hs, and G25K [20]. These proteins play a critical role in the regulation of the cytoskeleton [20] as well as in signal transduction of different stimuli [21]. Interestingly, some of the Rho proteins are able to induce transformation of cells in culture and are tumorigenic in vivo [22]. The exact mechanism of Rho activation is unclear but at least in some instances they localize downstream of Ras [2325]. Rho proteins are involved in the activation of c-Jun $\mathrm{N}$-terminal kinase (JNK) and the transcription factors $\mathrm{NF}-\kappa \mathrm{B}[26,27]$ and serum response factor $[28,29]$. However, elucidation of the direct targets for these proteins is only just beginning.
The Ras superfamily of proteins is involved not only in induction of the transformed phenotype, but also in the acquisition of metastatic behavior which can be considered the last step in tumoral progression. The possible role of several members of the Ras superfamily in the generation of metastasis is discussed here, with a focus on the molecular mechanisms by which they contribute to this process.

\section{Role of the Ras superfamily in metastasis}

\section{Steps in the metastatic process}

The generation of metastasis is a complex process, which involves several subsequent steps, as shown schematically in figure 1, that allow a cell to escape from the primary tumor, travel through the blood or lymph vessels, and establish a secondary tumor in a distant location [30]. Invasion is the first step toward metastasis and it requires loss of normal cell-to-cell interactions to allow individual cells to emigrate from the tumoral mass. Special organizations of the extracellular matrix (ECM), e.g., basement membranes, are barriers that tumors have to destroy to gain access to adjacent or distant organs. In most cases, this last event defines the malignancy of a tumor because it is usually the cause of death in cancer patients [31]. Invasive tumoral cells can degrade the ECM by altering the normal equilibrium of the ECM-degradative enzymes (see Johansson et al. and Andreasen et al. in this multi-author review). Tumoral cells find their way to distant organs following the blood or lymphatic circulation. In both cases, the first step consists of permeation of the vessels. This process is facilitated by the newly formed blood vessels in the tumor, a phenomenon called angiogenesis. Survival in the blood stream is the next challenge that tumoral cells have to face before reaching a new location. The establishment of a secondary tumor requires not only the ability of the cells to invade, but also to survive and proliferate in a distant location, usually a different organ in which they have to adapt to a new tissue environment.

\section{Involvement of Ras proteins in metastasis}

Ras proteins were first described as the products of the transforming oncogene in a rodent acute transforming retrovirus. Soon thereafter, ras oncogenes were identified as the transforming sequences from human tumor DNA [reviewed in ref. 2]. Many pioneer studies described how ras-transformed cells show some characteristics of the metastatic phenotype such as invasion of artificial basal membranes, and the ability to colonize the lung of mice following intravenous injection, an approach usually referred to as the experimental metas- 
tasis assay [32, 33]. However, this is a controversial issue, since not all ras-transformed cell lines show this behavior [32-37]. Moreover, when more physiological and stringent models, such as the spontaneous metastasis assay, were used to test their metastatic capability, in many cases ras failed to confer the full metastatic phenotype [34-39]. In the spontaneous metastasis assay, oncogene-transformed cells are injected subcutaneously in recipient animals. When the primary tumor reaches a fixed volume, it is resected and the animal is monitored for the development of metastasis. Thus this assay resembles more accurately natural tumor progression. One possible explanation for the conflicting results regarding the ability of Ras proteins to confer metastatic ability is the fact that different cell types were used in most studies. This may imply that ras itself is not sufficient and needs to cooperate with other pre-existing factors which are present in only some of the cell types used [33]. In agreement with this idea, it has been shown that the expression of oncogenic ras in combination with c-myc in rat and hamster lung fibroblasts confers on cells a metastatic potential, while expression of ras or $m y c$ alone fails to confer the metastatic phenotype [39].

Alternatively, ras could be responsible for the full metastatic phenotype indirectly, by promoting the acquisition of cumulative alterations in cellular pathways that can not only transform a cell, but also confer metastatic capability. Supporting this hypothesis, transformation of nonmetastatic rat mammary [40] and prostatic [41] cancer cells with oncogenic ras does not always correlate with the acquisition of metastatic ability but it does correlate with ras-induced chromosomal abnormalities. Thus, ras affected metastatic ability indirectly, presumably by promoting genetic instability. The hypothesis that ras induces some cellular change that is ultimately responsible for the induction of metastasis is further supported by studies in which ras-transformed cells that had acquired the metastatic phenotype but lost ras expression retained the metastatic phenotype [42].

Independent of the mechanism involved, the participation of Ras proteins in the progression of human cancers has been extensively studied. Analysis of clinical

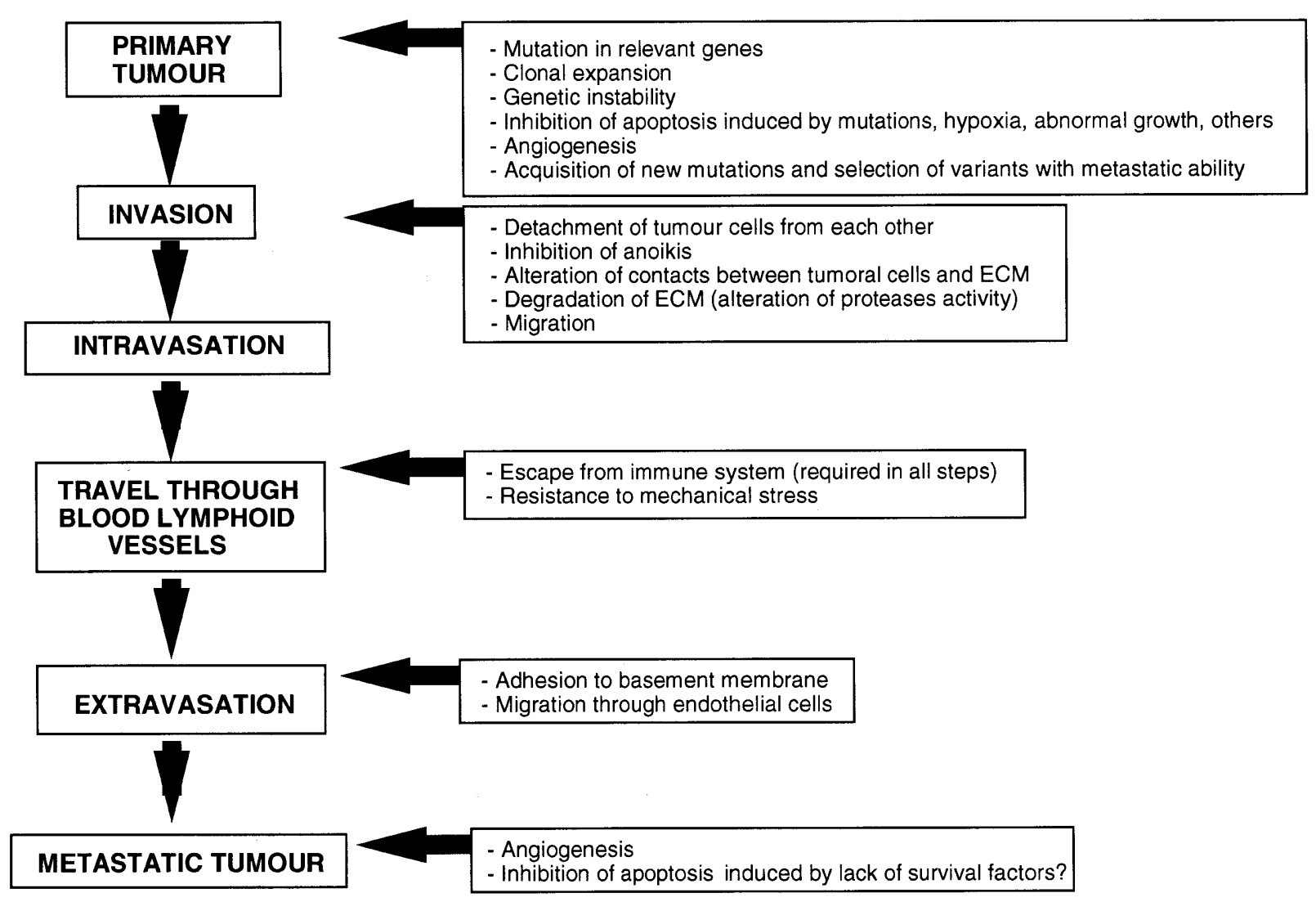

Figure 1. Steps in tumoral progression towards metastasis. The basic steps that cells have to complete to give rise to metastasis are boxed. Primary tumors usually contain a heterogeneous mixture of cells, and mutant clones with specific characteristics arise during tumorigenesis. The selection in tumors promotes the overgrowth of only some of the variant clones that have developed a selective advantage. The alterations that cells have to acquire to successfully complete each step are indicated on the right. 
samples has revealed a statistical association between increased Ras function (overexpression and/or activating mutations) and metastasis in a wide array of human malignancies such as carcinomas of the colon [43, 44], cervix [45], breast [46, 47] and stomach [48]. All these studies suggest that Ras oncoproteins play an important role not only in the generation but also in the progression of human cancers.

\section{Involvement of Rho proteins in metastasis}

In addition to ras, the rho family of genes are also able to promote cellular transformation, although with much less potency $[22,49]$. In contrast to ras, no mutation in the rho genes has been found in association with human cancer, although overexpression of the rho $\mathrm{C}$ gene is associated with the progression of human pancreatic carcinoma [50]. Recent studies suggest that Rho proteins mediate some of the effects of ras oncogenes in transformation [23]. Consistently, dominant negative forms of these proteins block ras-induced transformation [24], whereas active forms cooperate with other Ras effectors such as the Ser/Thr kinase Raf to induce transformation $[25,51]$. Hence, at least part of the Ras transformation ability may be mediated by Rho proteins.

Probably because Rho proteins are not very potent oncogenes, their possible role in the induction of metastasis has received little attention. An elegant study aimed to search for genes involved in metastatic progression led to the discovery of Tiam-1 [52]. The sequence of the Tiam-1 protein suggested that it might function as an exchange factor for Rho proteins. Tiam-1 was then demonstrated to be an exchange factor for Rac proteins in vitro, and consistently activated forms of Rac protein were found to promote invasion in vitro [53, 54]. This was the first study showing that proteins of the Rho family may promote metastatic behavior, at least in vitro. Finally, it has recently been reported that transformation of mouse fibroblasts with different proteins of the Rho family as well as with oncogenes that function as exchange factors for these proteins results in the acquisition of a metastatic phenotype in vivo, even in the spontaneous metastasis assay [38]. As mentioned before, amplification of a gene of the rho family, rho $C$, is associated with metastatic progression in human pancreatic cancer [50], the first clinical evidence implicating these proteins in promoting metastasis.

\section{Molecular mechanisms by which Ras proteins affect metastasis}

\section{Effects on the cytoskeleton}

The homeostasis of a tissue is maintained by continuous exchange of signals between the cells and the ECM. This is necessary for the accurate coordination of cells and stroma that distinguish a particular tissue. Most of this information is believed to be transmitted from the surface to the intracellular machinery by changes in the cytoskeleton. One of the most important features in the origin of a tumor is escape from this regulation, which leads to the autonomous proliferation of a clone of cells. The metastatic behavior can be considered as a further step in which the tumoral cells ignore not only the negative signals to proliferation but also to migration out of the original tissue. Again, the cytoskeleton plays an important role in motility and invasion, and the Ras superfamily of GTPases has been implicated in these processes. In fact, an effect on the cytoskeleton was the first function attributed to the Rho family of proteins [20]. The first studies demonstrated that Rho stimulates the organization of actin stress fibers, Rac induces the formation of lamellipodia, and $\mathrm{Cdc} 42$ is responsible for the appearance of filopodia $[55,56]$. These proteins can act in a coordinate fashion to provide motility to the cell, and a cascade of activation has been described from Cdc42 through Rac to Rho.

Adhesion: cell-cell/cell-ECM. The interaction of cells with the ECM is mediated by contacts between cellular surface proteins called integrins and components of the ECM like laminin or fibronectin. Integrins are adhesion molecules present as heterodimers that upon activation by binding to specific extracellular ligands can influence intracellular signaling pathways. They can modulate not only motility and other functions associated with the cytoskeleton, but also proliferation of the cell [57-59]. Integrins cluster in cellular structures called focal complexes whose formation is stimulated by Rho, Rac, and Cdc42. These complexes constitute a physical and functional connection between the extracellular and intracellular environments, as suggested by the association of important molecules such as PI3K, focal adhesion kinase (FAK), and members of the MAPK cascade [57, 59]. This mutual influence can be executed from inside to outside, because the affinity of integrins for their extracellular ligands can be modulated by events coming from inside the cell [59]. The relationship between integrins and members of the Ras superfamily of GTPases in driving changes in the cell-ECM interaction has recently been emphasized for different cell lines like fibroblasts [60] and lymphocytes [61].

Malignant cells often present imbalances in this delicate equilibrium, with activation of aberrant pathways leading to invasion and metastasis. Members of the Rho family of GTPases can participate in these processes. The activation of integrin $\alpha 6 \beta 1$ by laminin promotes tyrosine phosphorylation of a GTPase-activating protein for Rho, resulting in activation of the $G$ protein and promotion of changes in the cytoskeleton leading to formation of membrane-protrusive structures called 
invadipodia [62]. In addition, in vitro studies using mammary epithelial cells in a collagenous matrix have revealed that $\mathrm{Cdc} 42$ and Rac can mediate invasiveness by activation of PI3K in an integrin-mediated pathway [55].

Cadherins are calcium-dependent homophylic cell-cell adhesion molecules whose altered function has been implicated in the pathogenesis of metastasis. E-cadherin is believed to have anti-invasive activity. Ras superfamily involvement in cadherin-mediated adhesion is controversial. Some reports indicate an inhibitory role for Rho [63], Cdc42 and Rac [64] in this process, while others describe opposing effects $[65,66]$. The use of different cell lines could lie behind some of these discrepancies. They may in addition reflect the complex dynamics of these processes, because invasion needs constant remodeling of the cytoskeleton and the attachment/detachment of cells to the ECM.

Ras proteins can moreover modulate the adhesion of tumoral cells by increasing the expression of the surface glycoprotein CD44 and increasing the frequency of splicing variants which are implicated in metastasis [67]. Finally, Ras, Rac and PI3K have been shown to mediate the antiadhesion activity of the prometastatic ligand hepatocyte growth factor/scatter factor (HGF/ SF) [68]. HGF binds to the product of the protooncogene met, a tyrosine kinase receptor that upon activation promotes the cell dissociation of many epithelial cells. It has important physiological functions in embryogenesis, when specific populations of cells need to migrate and proliferate in locations different from their original tissue. This behavior resembles the metastatic phenotype and, in fact, overexpression of Met has been detected in several human cancers [69, 70].

Migration. The modulation of cytoskeleton organization and adhesion to substrates can greatly determine the motility of cells. It is therefore not surprising that Rac and Ras have been implicated in the chemotactic response to platelet-derived growth factor (PDGF) $[71,72]$. This process can be mediated by the enzymes phospholipase C- $\gamma$ (PLC- $\gamma$ ) and PI3K, whereas GAP has an inhibitory effect, in keeping with the participation of Ras in migration. Moreover, MAPK, one of the downstream components of the Ras signaling pathways, can induce the activating phosphorylation of the myosin light chain (MLC) kinase (MLCK), which in turn phosphorylates and activates MLC resulting in enhanced motility [73]. Rho-associated kinase, a proposed effector of Rho, is able to directly phosphorylate MLC and induce contractility in smooth muscle cells [74]. In addition, Rho A-overexpressing rat hepatoma cells show enhanced phosphorylation of MLC, and inhibitors of MLCK reduce their invasiveness [75].
PTEN, a recently identified tumor suppressor gene found mutated in many human tumors [76], codes for a phosphatase that removes the phosphate in position D3 of the phosphatidyl-inositol 3,4,5-triphosphate (PI 3,4,5-P3) [77]. This lipid is the product of PI3K and has an important role as a second messenger. Rac-1 is one of the molecules activated by PI 3,4,5-P3 [78]. Interestingly, overexpression of PTEN blocks migration [79] while active forms of Rac-1 have been shown to promote migration [55], suggesting that PTEN may prevent migration by removing the lipid second messenger PI 3,4,5-P3 that activates Rac-1. Consistently, $P T E N$ is mutated as a late event during tumorigenesis [76], implying that inactivation of this gene is required for some of the late events of tumor progression such as the generation of metastasis.

Intra/extravasation. The ability of cancer cells to cross the capillary wall and migrate into/out of lymphatic and blood vessels is conceptually a very important property for the metastatic phenotype. However, some recent data suggest that this might not be a limiting step in the development of metastasis. When metastatic ras-transformed fibroblasts and control fibroblasts were compared, both showed the same ability to extravasate from the capillary plexus of chicken embryo chorioallantoic membrane [80]. In addition, when $\mathrm{B} 16 \mathrm{~F} 1$ melanoma cells were injected in the portal vein of mice, $80 \%$ were able to survive in the liver microcirculation and extravasate by day 3 . In this model system, the most stringent step for the development of macroscopic metastasis was the survival and proliferation of cells once they reached the liver [81].

The study of this phenomenon is hampered by the difficulty establishing good in vitro models. There are a few reports that directly implicate members of the Ras superfamily of GTPases like Rho [75] and Cdc42 [82] in the invasion of cell monolayers (transmigration). However, an emerging concept in this field is that adhesion molecules like integrins and cadherins play important roles, and that endothelial cells are not passive elements in this process [83].

\section{Effects on gene expression}

Induction of proteases. Apart from effects on the cytoskeleton, members of the Ras family of GTPases can modulate the expression of genes involved in some of the metastatic steps. Among these are several types of protease whose function is the degradation of ECM components. These enzymes are physiologically expressed by macrophages and other cells in the context of inflammation, wound healing, and other circumstances requiring remodeling of tissue. The same or 
more specific proteases can assist invasion of metastatic cells. These cells can shift the proteolytic balance of the surrounding tissue by direct production of the proteases, by inducing their secretion in stromal fibroblast, or by reducing protease inhibitors [84].

There is abundant information linking the ras oncogene with the expression of proteases and tumor invasion. The 92-kDa type IV collagenase/gelatinase $\mathrm{B} /$ matrix metalloproteinase-9 (MMP-9) is one MMP most frequently associated with Ras [85-91]. Overexpression of the $72-\mathrm{kDa}$ MMP-2 has also been linked to this oncogene in vitro [86] and in human malignancy [45]. Laminin induces the expression of MMP-2 through phospholipase D (PLD), an enzyme that cleaves phosphatidylcholine into PA and choline [92]. In agreement with this mechanism of activation, the intracellular liberation of PA increases the release of MMP-2 in metastatic fibrosarcoma cells [93]. Interestingly, activated forms of Rho [94, 95] and Ras [96-99] proteins have been proposed to induce the activation of PLD, raising the possibility that PLD acts as a link between oncogenic Ras proteins and protease induction. Another MMP, matrilysin (MMP-7), was induced by Ras transfection in colon cancer cells by an AP-1-dependent pathway [100]. Ras may also mediate the upregulation of proteases induced by physiological stimuli. The list of tissue proteases induced by Ras includes urokinase or tissue-type plasminogen activators, depending on the cells studied [101, 102], and the cysteine proteases cathepsin C and L [103, 104]. As mentioned above, Ras can also alter the proteolytic balance causing a reduction in the levels of tissue inhibitors of metalloproteinases (TIMPs) and cystatins [91, 105, 106].

Induction of other genes. In addition to proteases, many other metastasis-related genes have been found to be regulated by Ras proteins. Ras induces the expression of metastasis-associated isoforms of the adhesion molecule CD44 [67, 87]. The expression of vascular endothelial growth factor (VEGF) correlates with the level of expression of activated Ras proteins in a model of mouse skin carcinogenesis [107]. VEGF is a potent angiogenic factor that promotes the growth of new blood vessels, a step required in the generation of metastasis [1]. Expression of $n m-23$, a gene involved in suppression of the metastatic phenotype, is repressed by Ras [87, 105]. Interestingly, several studies [108] demonstrate that adenovirus E1a protein blocks these alterations in gene expression and prevents Ras-induced metastatic behavior without affecting its tumorogenic potential [109]. In addition, this viral protein is able to block the Ras-induced transcriptional activation of several ECM proteases that may be important for the development of metastasis [90, 110]. Little is known about the coordination of migration and degradative processes. However, fibronectin was recently shown to induce the secretion of MMP-9 in ovarian cancer cells in a FAK- and Ras-dependent pathway [111].

Inhibition of apoptosis. Apoptosis is the process by which a cell dies in a neat orderly way that does not alter the structure or function of the tissue in which it is located [112]. The induction of apoptosis is an important mechanism to control cell number and delete unwanted cells [113, 114]. The apoptosis program is believed to be latent in all cells and has to be constantly suppressed by extracellular survival signals in order to keep cells alive. The survival signals from the environment are very diverse, and include growth factors, cytokines, hormones, and contacts between cells and between the cells and the ECM. Hence each cell type constantly receives from its normal environment the required survival signals that prevent the activation of the endogenous apoptotic program $[113,114]$. This system is very useful for controlling the number of cells in a tissue. Since the survival signals are limited, they can support only a limited, fixed number of cells. This system also ensures that the cells are in the appropriate location. Misplaced cells fail to receive the appropriate survival signals and die. The usefulness of this system is especially apparent during the development of the central nervous system where an excess neurons are produced, but only those that are able to make the correct contacts receive the required survival factors and survive. The remainder are eliminated by apoptosis without compromising the integrity of the tissue. Thus this apoptosis by default regulates both the total number of neurons and their localization.

As expected, alteration of the normal apoptotic pathways has a profound impact in tumorogenesis at many levels $[115,116]$. Failure to undergo apoptosis results in the accumulation of cells leading to the formation of a tumor. Bcl-2 is a critical protein in the apoptotic machinery that promotes survival. Overexpression of $\mathrm{Bcl}-2$ due to certain chromosomal translocations results in the generation of human lymphomas and leukemias [117119]. But apoptosis has been implicated not only in the initiation of tumors but also in their progression. Tumoral cells usually present genetic instability and the accumulation of mutations is critical for the generation of new clonal cell populations with more aggressive behavior. Under normal conditions, seriously damaged cells undergo apoptosis. Disruption of this process leads to the accumulation of cells that bear unrepaired mutations.

The alteration of the normal apoptotic response also plays an important role in the development of metastasis. As discussed above, cells are tightly attached to one another and to the ECM. Disruption of these cell-cell contacts and alterations in adhesion to the ECM are first steps toward metastasis. Importantly, these interactions are strong survival signals and most adherent cells 
require these contacts to survive. The term anoikis refers to the induction of apoptosis by detachment of cells [120-122]. Hence, to metastasize, cells have to avoid the induction of apoptosis due to the lack of normal cell-cell and cell-ECM contacts. Ras oncoproteins are able to prevent anoikis in epithelial cells upon detachment [123] by activating a potent survival signal through the activation of PI3K [123]. Thus, activated Ras proteins contribute to the generation of metastasis by inhibiting apoptosis. Moreover, cell transformation usually increases the sensitivity of cells to apoptotic stimuli, which could be an evolutionarily developed mechanism to prevent unwanted cell division [124]. Transformation of cells with the myc oncogene, which is present in a large number of human malignancies, renders cells extremely sensitive to apoptosis [125, 126]. Transfection of active Ras proteins in $m y c$-transformed cells completely abolishes the Myc-mediated sensitivity to apoptosis [127]. This cooperation between oncogenes may be crucial for the completion of the different steps during tumor progression, and it may be more than a mere coincidence that, at least in some systems, generation of metastasis requires both ras and myc oncogenes (see above).

A number of other steps during tumor progression are limited by the induction of apoptosis. A characteristic of most solid tumors is that the internal part of the tumor is usually hypoxic, a condition that may induce apoptosis. Development of metastasis in distant tissues and, usually, organs different from the original one, imply growth of tumoral cells in an unfamiliar environment that probably lack the required specific survival signals. No literature is available on the effect of Ras proteins in these situations; however, the fact that Ras proteins activate a potent antiapoptotic pathway [123, 127] suggests that ras oncogenes may help to prevent apoptosis in these situations. Supporting this idea, ras oncogenes have been shown to render cells resistant to the killing effect of many chemotherapeutic drugs [128]. Finally, members of the Rho family of GTPases have been demonstrated to induce apoptosis under conditions of serum deprivation [129-131]. Although the physiological role of this effect must be further characterized, knowledge of the signal transduction pathways altered by either Ras or Rho proteins may be essential for understanding the regulation of proliferating versus apoptotic signals [132], which may in turn bring some light to bear on understanding the onset of metastasis. Most anticancer drugs kill cells by activating the endogenous apoptotic program, and development of resistance to these therapies seems to be due to disruption of the normal apoptotic program or activation of antiapoptotic pathways [133].

\section{Conclusions}

Study of the mechanisms leading to the acquisition of a metastatic phenotype in tumoral cells is one of the major topics in cancer research. It constitutes a prerequisite for the development of new therapeutic agents aimed to inhibit the establishment and growth of metastases once a primary cancer has been diagnosed. The data available so far have only started to reveal the complexity of this multistep process. The Ras superfamily of GTPases has been implicated in virtually all the events related to cancer metastasis (a schematic representation of their involvement is depicted in figure 2). This is mostly due to the involvement of these proteins in the control of both proliferation and motility of cells. However, one of the emerging concepts in the field is that cellular transformation and metastatic potential are governed by independent pathways. If true, this fact could have major relevance in anticancer drug design and, hopefully, in the future treatment of cancer patients.

Ras is the small GTP-binding protein most extensively studied as an inducer of cellular transformation. Most recently, effort has been focused in elucidating its participation in specific steps of the metastatic process. Ras has been implicated in virtually all of these steps, but the underlying mechanism is not clear. The existence of a genetic program of 'invasive growth' directly activated by Ras is one possibility, but there is no evidence supporting this hypothesis. In fact, there are many circumstances in which Ras itself is not able to confer a full metastatic phenotype, and it must then work in cooperation with other cellular alterations. Alternatively, the multiple prometastatic effects of Ras may result from its induction of genetic instability in cells, a phenomenon strongly correlated with tumor progression. Hence, the use of Ras as a putative target for new therapeutic agents could have a heterogeneous effect in advanced cancers, where tumoral cells have already accumulated several genetic lesions.

The Rho family of GTPases shares some of the characteristics described for Ras, but its contribution to the metastatic phenotype has been classically related to effects on the cytoskeleton. However, the participation of Rho proteins in prometastatic signaling pathways could be more complex. They can mediate some of the events associated with Ras-induced transformation and at the same time play critical roles in cell adhesion molecule pathways. Hence, overexpression or deregulation of the active forms of these proteins may be partly responsible for the aberrant cell-cell and cell-ECM relationships typical of metastatic cells. More detailed knowledge of these pathways should lead to the identification of targets for new pharmacological or genetic antimetastatic agents. 


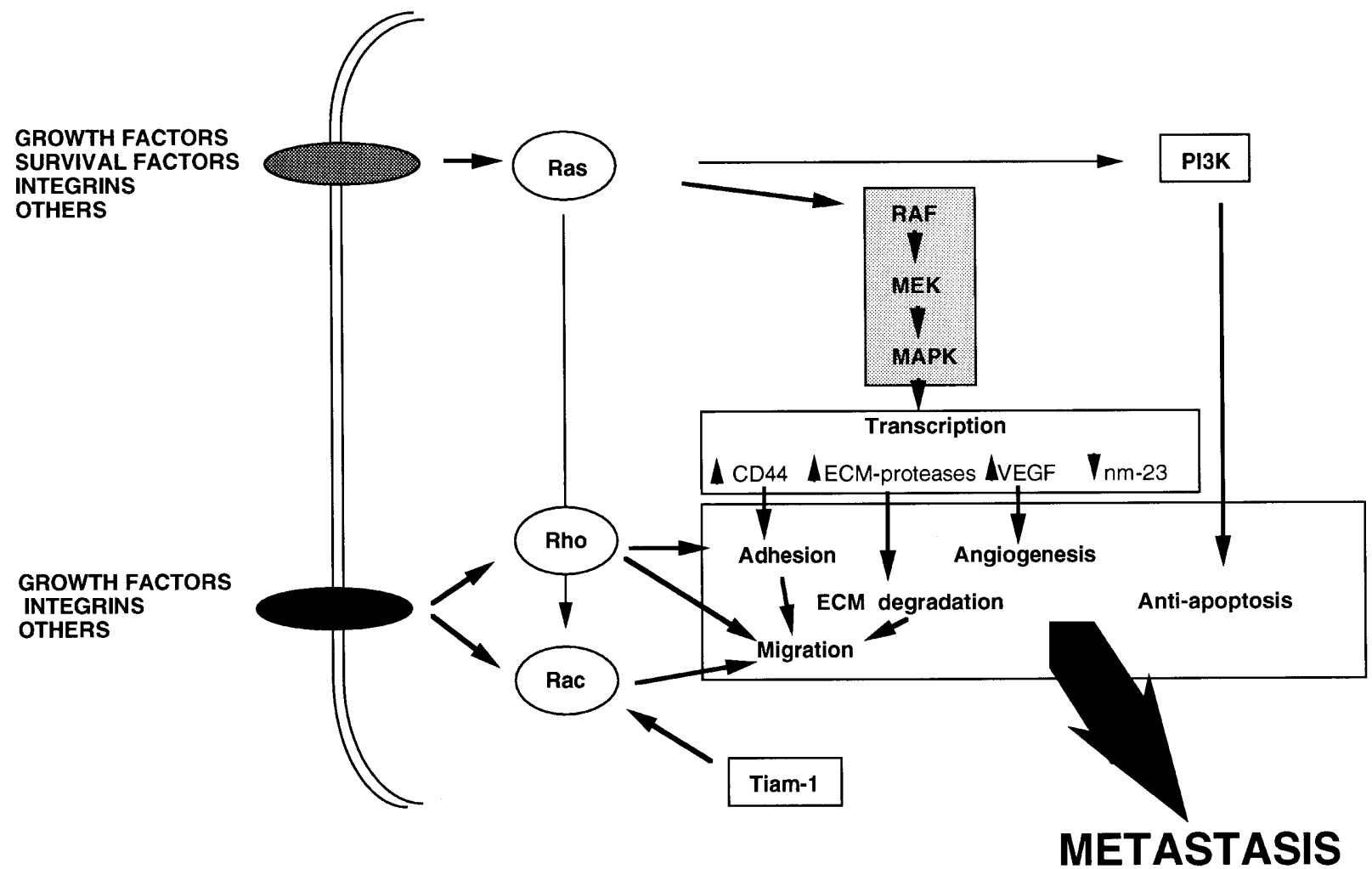

Figure 2. Role of proteins of the Ras superfamily in the activation of intracellular pathways that contribute to metastasis. Only some selected pathways are indicated. Note that not all the described interactions between difference pathways are shown (e.g., Rac may be activated by PI3K products, and PI3K has been shown to be activated by members of the Rho family). Members of the Rho family mediate some of the Ras effects on cells, thus they can be placed downstream of Ras. See main text for details.

Several factors contribute to the complexity of this field. First, the large number of members of the Ras superfamily of GTPases and the cross-talk between the signal transduction pathways in which they can participate. Second, the inherent complexity of the metastastic process, which requires coordination of different cellular functions such as migration, proteolysis of ECM, proliferation, and inhibition of apoptosis. Whether there is a critical element that triggers all these cellular alterations, and the possible involvement of the Ras GTPases in this putative initiation event are unresolved. Finally, the currently used models to study the metastatic phenotype are poorly standardized, and the different backgrounds of the cell lines employed can generate contradictory results. Hence, much more work is needed for a clear picture of the importance of the Ras family of GTPases in invasion and metastasis to emerge. A combination of reliable in vitro and especially in vivo models with clinical data will surely contribute to this goal in the near future.

Acknowledgements. This study has been supported by the following grants: SAF98-0112-CO2-01, FIS96/2136, CAM 08.1/0024/97 and CAM 08.1/0045.1/98.
1 Kumar V., Cotran R. S. and Robbins S. L. (1997) Neoplasia. In: Basic Pathology, 6th edn, pp. 531-580, Saunders, St. Louis, Mo

2 Lacal J. C. and Tronick S. R. (1988) The ras oncogene. In: The Oncogene Handbook, pp. 255-304, 535-550, Reddy E. P., Skalka A. M. and Curran T. (eds), Elsevier, Amsterdam

3 Cuadraro A., Carnero A. and Lacal J. C. (1993) ras-p21 proteins: switch devices for signal transduction. In: The ras Superfamily of GTPases, pp. 119-153, Lacal J. C. and McCormick F. (eds), CRC, Boca Raton, Fla

4 Grand R. J. A. and Owen D. (1991) The biochemistry of ras p21. Biochem. J. 279: 609-631

5 Casey P. J., Solski P. A., Der C. J. and Buss J. E. (1989) p21 ras is modified by a farnesyl isoprenoid. Proc. Natl. Acad. Sci. USA 86: $8323-8327$

6 Cox A. D., Hisaka M. M., Buss J. E. and Der C. J. (1992) Specific isoprenoid modification is required for function of normal, but not oncogenic, Ras protein. Mol. Cell. Biol. 12: 2606-2615

7 Morrison D. K., Kaplan D. R., Rapp U. R. and Roberts T. M. (1988) Signal transduction from membrane to cytoplasm: growth factors and membrane bound oncogene products increase phosphorylation and associated kinase activity. Proc. Nat. Acad. Sci. USA 85: $8855-8859$

8 Gale N. W., Kaplan S., Lowenstein E. J., Schlessinger J. and Bar-Sagi D. (1993) Grb2 mediates the EGF-dependent activation of guanine nucleotide exchange on ras. Nature 363: 88-92

9 Rozakis-Adcock M., Fernley R., Wade J., Pawson T. and Bowtell D. (1993) The SH2 and SH3 domains of mammalian Grb2 couple the EGF receptor to the ras activator mSos1. Nature 363: $83-85$ 
10 Egan S. E., Giddins B. W., Brooks M. W., Buday L., Sizelan A. M. and Weinber R. A. (1993) Asociation of Sos ras exchange protein with Grb2 is implicated in tyrosine kinase signal transduction and transformation. Nature 363: 45-51

11 Aelst L. V., Barr M., Marcus S., Polverino A. and Wigler M. (1993) Complex formation between ras and raf and other protein kinases. Proc. Nat. Acad. Sci. USA 90: 6213-6217

12 Troppmair J., Bruder J. T., App H., Cai H., Liptak L., Szeberényi J. et al. (1992) Ras controls coupling of growth factor receptors and protein kinase $\mathrm{C}$ in the membrane to raf-1 and B-raf protein serine kinases in the cytosol. Oncogene 7: $1867-1873$

13 Moodie S. A., Willumsen B. M., Weber M. J. and Wolfman A. (1993) Complexes of ras-GDP with raf-1 and the mitogen activated protein kinase kinase. Science 260: $1658-1660$

14 Hofer F., Fields S., Schneider C. and Martin G. S. (1994) Activated Ras interacts with the Ral guanine nucleotide dissociation stimulator. Proc. Natl. Acad. Sci. USA 91: 11089-11093

15 Kikuchi A., Demo S. D., Ye Z. H., Chen Y. W. and Wiliams L. T. (1994) ralGDS family members interact with the effector loop of ras p21. Mol. Cell. Biol. 14: 7483-7491

16 Rodriguez-Viciana P., Warne P. H., Dhand R., Vanhaesebroeck B., Gout I., Fry M. J. et al. (1994) Phosphatidylinositol-3-OH kinase as a direct target of Ras. Nature 370: $527-532$

17 Gille H., Sharrocks A. D. and Shaw P. E. (1992) Phosphorylation of transcription factor $\mathrm{p} 62^{\mathrm{TCF}}$ by MAP kinase stimulates ternary complex formation at c-fos promoter. Nature 358: $414-417$

18 Burgering B. M. T. and Coffer P. J. (1995) Protein kinase B (c-Akt) in phosphatidylinositol-3-OH kinase signal transduction. Nature 376: 599-602

19 Jiang H., Luo J. Q., Urano T., Frankel P., Lu Z., Foster D. A. et al. (1995) Involvement of Ral GTPase in v-Src-induced phospholipase D activation. Nature 378: 409-412

20 Takai Y., Takuya S., Tanaka K. and Nakanishi H. (1995) Rho as a regulator of the cytoskeleton. Trends Biochem. Sci. 20: $227-231$

21 Van Aelst L. and D'Souza-Schorey C. (1997) Rho GTPases and signaling networks. Genes Dev. 11: 2295-2322

22 Perona R., Esteve P., Jiménez B., Ballestero R. P. and Lacal J. C. (1993) Tumorigenic activity of rho genes from Aplysia californica. Oncogene 8: 1285-1292

23 Khosravi-far R., Solski P. A., Clark G. J., Kinch M. S. and Der C. J. (1995) Activation of Rac1, RhoA. and mitogen-activated protein kinases is required for Ras transformation. Mol. Cell. Biol. 15: 6443-6453

24 Prendergast G. C., Khosravi-Far R., Solski P. A., Kurzawa H., Lebowitz P. F. and Der C. J. (1995) Critical role of Rho in cell transformation by oncogenic Ras. Oncogene 10: 2289-2296

25 Qiu R. G., Chen J., Kirn D., McCormick F. and Symons M. (1995) An essential role for Rac in Ras transformation. Nature 374: 457-459

26 Perona R., Montaner S., Saniger L., Sanchez-Perez I., Bravo R. and Lacal J. C. (1997) Activation of the nuclear factorkappaB by Rho, CDC42, and Rac-1 proteins. Genes Dev. 11: $463-475$

27 Montaner S., Perona R., Saniger L. and Lacal J. C. (1998) Multiple signalling pathways lead to the activation of the nuclear factor kappaB by the Rho family of GTPases. J. Biol. Chem. 273: 12779-12785

28 Hill C. S., Wynne J. and Treisman R. (1995) The Rho family GTPases RhoA, Rac1, and $\mathrm{CDC} 42 \mathrm{Hs}$ regulate transcriptional activation by SRF. Cell 81: $1159-1170$

29 Montaner S., Perona R., Saniger L. and Lacal J. C. (1999) Activation of serum response factor by RhoA is mediated by the NF- $\kappa \mathrm{B}$ and $\mathrm{C} / \mathrm{EBP}$ transcription factors. J. Biol. Chem. 274: $8506-8515$

30 Woodhouse E. C., Chuaqui R. F. and Liotta L. A. (1997) General mechanisms of metastasis. Cancer 80: 1529-1537
31 De Vita V., Hellman S. and Rosenberg S. A. (1993) Principles and Practice of Oncology, 4th edn, Lippincott, Philadelphia

32 Bondy G. P., Wilson S. and Chambers A. F. (1985) Experimental metastatic ability of H-ras-transformed NIH 3T3 cells. Cancer Res. 45: 6005-6009

33 Muschel R. J., Williams J. E., Lowy D. R. and Liotta L. A. (1985) Harvey ras induction of metastatic potential depends upon oncogene activation and the type of recipient cell. Am. J. Pathool. 121: 1-8

34 Tatsuka M., Ota T., Yamagishi N., Kashihara Y., Wada M., Matsuda N. et al. (1996) Different metastatic potentials of ras- and src-transformed BALB/c 3T3 A31 cells. Mole. Carcinogenesis 15: 300-308

35 Ballin M., Mackay A. R., Hartzler J. L., Nason A., Pelina M. D. and Thorgeirsson U. P. (1991) Ras levels and metalloproteinase activity in normal versus neoplastic ras mammary tissues. Clin. Exp. Metastasis 9: 179-189

36 Price J. E., Aukerman S. L., Ananthaswamy H. N., McIntyre B. W., Schackert G., Schackert H. K. et al. (1989) Metastatic potential of cloned murine melanoma cells transfected with activated c-Ha-ras. Cancer Res. 49: 4274-4281

37 Wallace J. S., Hayle A. J., Syms A. J., Cairney M., Tutty B., Gazzard A. et al. (1989) The ras oncogene and tumor metastasis: observations on murine cells transfected with activated human c-Ha-ras. Differentiation 41: 208-215

38 Peso L. del, Hernandez-Alcoceba R., Embade N., Carnero A., Esteve P., Paje C. et al. (1997) Rho proteins induce metastatic properties in vivo. Oncogene 15: 3047-3057

39 Wyllie A. H., Rose K. A., Morris R. G., Steel C. M., Foster E. and Spandidos D. A. (1987) Rodent fibroblast tumours expressing human myc and ras genes: growth, metastasis and endogenous oncogene expression. Br. J. Cancer 56: 251-259

40 Ichikawa T., Kiprianou N. and Isaacs J. T. (1990) Genetic instability and the acquisition of metastatic ability by rat mammary cancer cells following v-H-ras oncogene transfection. Cancer Res. 50: 6349-6357

41 Ichikawa T., Schalken J. A., Ichikawa Y., Steinberg G. D. and Isaacs J. T. (1991) H-ras expression, genetic instability, and acquisition of metastatic ability by rat prostatic cancer cells following v-H-ras oncogene transfection. Prostate 18: $163-172$

42 Vousden K. H., Eccles S. A., Purvies H. and Marshall C. J. (1986) Enhanced spontaneous metastasis of mouse carcinoma cells transfected with an activated c-Ha-ras-1 gene. Int. J. Cancer 37: 425-433

43 Suchy B., Zietz C. and Rabes H. M. (1992) K-ras point mutations in human colorectal carcinomas: relation to aneuploidy and metastasis. Int. J. Cancer 52: 30-33

44 Michelassi F., Erroi F., Roncella M. and Block G. E. (1989) Ras oncogene and the acquisition of metastasizing properties by rectal adenocarcinoma. Dis. Colon Rectum 32: 665-668

45 Garzetti G. G., Ciavattini A., Lucarini G., Goteri G., Nictolis M. D., Romanini C. et al. (1998) Ras p21 immunostaining in early stage squamous cervical carcinoma: relationship with lymph nodal involvement and 72 kDa-metalloproteinase index. Anticancer Res. 18: 609-613

46 Shekhar P. V. and Miller F. R. (1994) Correlation of differences in modulation of ras expression with metastatic competence of mouse mammary tumor subpopulations. Invasion Metastasis 14: $27-37$

47 Lundy J, Grimson R., Mishriki Y., Chao S., Ovarez S., Fromowitz F. et al. (1986) Elevated ras oncogene expression correlates with lymph node metastases in breast cancer patients. J. Clin. Oncol. 4: 1321-1325

48 Deng G. R., Liu X. H. and Wang J. R. (1991) Correlation of mutations of oncogene c-Ha-ras at codon 12 with metastasis and survival of gastric cancer patients. Oncogene Res. 6: $33-38$

49 Ballestero R. P., Esteve P., Perona R., Jiménez B. and Lacal J. C. (1991) Biological function of Aplysia californica rho gene. In: The Superfamily of ras Related Genes, pp. 237242, NATO Advanced Science Institute Series, vol. A220, Plenum, New York. 
50 Suwa H., Ohshio G., Imamura T., Watanabe G., Arii S., Imamura M. et al. (1998) Overexpression of the rhoC gene correlates with progression of ductal adenocarcinoma of the pancreas. Br. J. Cancer 77: 147-152

51 Roux P., Gauthier-Rouviere C., Doucet-Brutin S. and Fort P. (1997) The small GTPases Cdc42Hs, Racl and RhoG delineate Raf-independent pathways that cooperate to transform NIH3T3 cells. Curr. Biol. 7: 629-637

52 Habets G. G. M., Scholtes E. H. M., Zuydgeest D., Kammen R. A. v. d., Stam J. C., Berns A. et al. (1994) Identification of an invasion-inducing gene, Tiam-1, that encodes a protein with homology to GDP-GTP exchangers for Rholike proteins. Cell 77: 537-549

53 Michiels F., Habets G. G. M., Stam J. C., van der Kammen R. A. and Collard J. G. (1995) A role for Rac in Tiam1-induced membrane ruffling and invasion. Nature 375: 338-340

54 Keely P. J., Westwick J. K., Whitehead I. P., Der C. J. and Parise L. V. (1997) Cdc42 and Racl induce integrin-mediated cell motility and invasiveness through PI(3)K. Nature 390: $632-636$

55 Kozma R., Ahmed S., Best A. and Lim L. (1995) The Ras-related protein $\mathrm{Cdc} 42 \mathrm{Hs}$ and bradykinin promote formation of peripheral actin microspikes and filopodia in Swiss 3T3 fibroblasts. Mol. Cell. Biol. 15: 1942-1952

56 Nobes C. D. and Hall A. (1995) Rho, rac, and cdc42 GTPases regulate the assembly of multimolecular focal complexes associated with actin stress fibers, lamellipodia, and filopodia. Cell 81: 53-56

57 Renshaw M. W., Toksoz D. and Schwartz M. A. (1996) Involvement of the small GTPase rho in integrin-mediated activation of mitogen-activated protein kinase., J. Biol. Chem. 271: 21691-21694

58 Keely P., Parise L. and Juliano R. (1998) Integrins and GTPases in tumour cell growth, motility and invasion. Trends Cell Biol. 8: 101-106

59 Clark E. A., King W. G., Brugge J. S., Symons M. and Hynes R. O. (1998) Integrin-mediated signals regulated by members of the rho family of GTPases. J. Cell. Biol. 142: $573-586$

60 Sharma S. V. (1998) Rapid recruitment of p120RasGAP and its associated protein, p190RhoGAP, to the cytoskeleton during integrin mediated cell-substrate interaction. Oncogene 17: $271-281$

61 D'Souza-Schorey C., Boettner B. and Van Aelst L. (1998) Rac regulates integrin-mediated spreading and increased adhesion of T lymphocytes. Mol. Cell. Biol. 18: 3936-3946

62 Nakahara H., Mueller S. C., Nomizu M., Yamada Y., Yeh Y. and Chen W. T. (1998) Activation of betal integrin stimulates tyrosine phosphorylation of p190RhoGAP and membrane-protusive activities at invadipodia. J. Biol. Chem. 273: $9-12$

63 Tokman M. G., Porter R. A. and Williams C. L. (1997) Regulation of cadherin-mediated adhesion by the small GTP-binding protein Rho in small cell lung carcinoma cells. Cancer Res. 57: 1785-1793

64 Kuroda S., Fukata M., Nakagawa M., Fujii K., Nakamura T., Ookubo T. et al. (1998) Role of IQGAP1, a target of the small GTPases Cdc42 and Rac1, in regulation of E-cadherinmediated cell-cell adhesion. Science 281: $832-835$

65 Kuroda S., Fukata M., Fujii K., Nakamura T., Izawa I. and Kaibuchi K. (1997) Regulation of cell-cell adhesion of MDCK cells by Cdc42 and Rac1 small GTPases. Biochem. Biophys. 240: 430-435

66 Horkijk P. L., Klooster J. P . ten, Kammen R. A. van der, Michelis F., Oomen L. C. and Collard J. G. (1997) Inhibition of invasion of epithelial cells by Tiam1-Rac signaling. Science 278: $1464-1466$

67 Hofmann M., Rudy W., Gunthert U., Zimmer S. G., Zawadzki V., Zoller M. et al. (1993) A link between ras and metastatic behaviour of tumor cells: ras induces CD44 promoter activity and leads to low-level expression of metastasis-specific variants of CD44 in CREF cells. Cancer Res. 53: $1516-1521$
68 Potempa S. and Ridley A. J. (1998) Activation of both MAP kinase and phosphatidylinositide 3-kinase by Ras is required for hepatocyte growth factor/scatter factor-induced adherens junction disassembly. Mol. Biol. Cell. 9: 2185-2200

69 Giordano S., Bardelli A., Zhen Z., Menard S., Ponzetto C. and Comoglio P. M. (1997) A point mutation in the MET oncogene abrogates metastasis without affecting transformation. Proc. Natl. Acad. Sci. USA 94: 13868-13872

70 To C. T. and Tsao M. S. (1998) The roles of hepatocyte growth factor/scatter factor and met receptor in human cancers. Oncol. Rep. 5: 1013-1024

71 Anand-Apte B., Zetter B. R., Viswanathan A., Qiu R. G., Chen J., Ruggieri R. et al. (1997) Platelet-derived growth factor and fibronectin-stimulated migration are differentially regulated by $\mathrm{Rac}$ and extracellular signal-regulated kinase pathways. J. Biol. Chem. 272: 30688-30692

72 Kundra V., Anand-Apte B., Feig L. A. and Zetter B. R. (1995) The chemotactic response to PDGFBB: evidence of a role for Ras. J. Cell Biol. 130: 725-731

73 Klemke R. L., Cai S., Giannini A. L., Gallagher P. J., de Lanerolle P. and Cheresh D. A. (1997) Regulation of cell motility by mitogen-activated protein kinase. J. Cell Biol. 137: $481-492$

74 Kureishi Y., Kobayashi S., Amano M., Kimura K., Kanaide H. and Nakano T. et al. (1997) Rho-associated kinase directly induces smooth muscle contraction through myosin light chain phosphorylation. 272: 12257-12260

75 Yoshioka K., Matsumura F., Akedo H. and Itoh K. (1998) Small GTP-binding protein Rho stimulates the actomyosin system, leading to invasion of tumor cells. J. Biol. Chem. 273: $5146-5154$

76 Di Cristofano A., Pesce B., Cordon-Cardo C. and Pandolfi P. P. (1998) Pten is essential for embryonic development and tumour suppression. Nat. Genet. 19: $348-355$

77 Maehama T. and Dixon J. E. (1998) The tumor suppressor, PTEN/MMAC1, dephosphorylates the lipid second messenger, phosphatidylinositol 3,4,5-trisphosphate. J. Biol. Chem. 273: $13375-13378$

78 Han J, Luby-Phelps K., Das B., Shu X., Xia Y., Mosteller R. D. et al. (1998) Role of substrates and products of PI 3-kinase in regulating activation of Rac-related guanosine triphosphatases by Vav. Science 279: $558-560$

79 Tamura M., Gu J., Matsumoto K., Aota S., Parsons R. and Yamada K. M. (1998) Inhibition of cell migration, spreading, and focal adhesions by tumor suppressor PTEN. Science 280: $1614-1617$

80 Koop S., Schmidt E. F., MacDonald I. C., Morris V. L., Khokha R., Grattan M. et al. (1996) Independence of metastatic ability and extravasation: metastatic ras-transformed and control fibroblasts extravasate equally well. Proc. Natl. Acad. Sci. USA 93: 11080-11084

81 Luzzi K. J., MacDonald I. C., Schmidt E. E., Kerkvliet N., Morris V. L., Chambers A. F. et al. (1998) Multistep nature of metastatic inefficiency: dormancy of solitary cells after succesful extravasation and limited survival of early micrometastases. Am. J. Pathol. 153: 865-873

82 Weber K. S., Klickstein L. B., Weber P. C. and Weber C. (1998) Chemokine-induced monocyte transmigration requires cdc42-mediated cytoskeletal changes. Eur. J. Immunol. 28: 2245-2251

83 Sandig M., Voura E. B., Kalnins V. I. and Siu C. H. (1997) Role of cadherins in the transendothelial migration of melanoma cells in culture. Cell Motil. Cytoskeleton 38: $351-364$

84 Himelstein B. P., Canete-Soler R., Bernhard E. J. and Muschel R. J. (1994) Induction of fibroblast $92 \mathrm{kDa}$ gelatinase/type IV collagenase expression by direct contact with metastatic tumor cells. J. Cell Sci. 107: 477-486

85 Giambernardi T. A., Grant G. M., Taylor G. P., Hay R. J., Maher V. M., McCormick J. J. et al. (1988) Overview of matrix metalloproteinase expression in cultured human cells. Matrix Biol. 16: 483-496 
86 Yanagihara K., Nii M., Tsumuraya M., Numoto M., Seito T. and Seyama T. (1995) A radiation-induced murine ovarian granulosa cell tumor line: introduction of v-ras gene potentiates a high metastatic ability. Jpn. J. Cancer Res. 86: $347-356$

87 Graff J. R., Boghaert E. R., De Benedetti A., Tudor D. L., Zimmer C. C., Chan S. K. et al. (1995) Reduction of translation initiation factor 4E decreases the malignancy of ras-transformed cloned embryo fibroblasts. Int. J. Cancer 60: $255-263$

88 Ballin M., Gomez D. E., Sinha C. C. and Thorgeirsson U. P. (1988) Ras oncogene mediated induction of a $92 \mathrm{kDa}$ metalloproteinase: strong correlation with the malignant phenotype. Biochem. Biophys. Res. Commun. 154: 832-838

89 Himelstein B. P., Lee E. J., Sato H., Seiki M. and Muschel R. J. (1997) Transcriptional activation of the matrix metalloproteinase- 9 gene in an $\mathrm{H}$-ras and v-myc transformed rat embryo cell line. Oncogene 14: 1995-1998

90 Bernhard E. J., Hagner B., Wong C., Lubenski I. and Muschel R. J. (1995) The effect of E1A transfection on MMP-9 expression and metastatic potential. Int. J. Cancer 60: $718-724$

91 Chambers A. and Tuck A. (1993) Ras-responsive genes and tumor metastasis. Crit. Rev. Oncog. 4: 95-114

92 Reich R., Blumenthal M. and Liscovitch M. (1995) Role of phospholipase $\mathrm{D}$ in laminin-induced production of gelatinase A (MMP-2) in metastatic cells. Clin. Exp. Metastasis 13: $134-140$

93 Williger B.-T., Reich R., Neeman M., Bercovici T. and Liscovitch M. (1995) Release of gelatinase A (matrix metalloproteinase 2) induced by photolysis of caged phosphatidic acid in HT 1080 metastatic fibrosarcoma cells. J. Biol. Chem. 270: $29656-29659$

94 Bowman E. P., Uhlinger D. J. and Lambeth J. D. (1993) Neutrophil phospholipase D is activated by a membrane-associated Rho family small molecular weight GTP-binding protein. J. Biol. Chem. 268: 21509-21512

95 Malcolm K. C., Ross A. H., Qiu R. G., Symons M. and Exton J. H. (1994) Activation of rat liver phospholipase D by the small GTP-binding protein RhoA. J. Biol. Chem. 269: 25951-25954

96 Carnero A., Cuadraro A., del Peso L. and Lacal J. C. (1994) Activation of type D phospholipase by serum stimulation and ras-induced transformation in NIH $3 \mathrm{~T} 3$ cells. Oncogene 9: $1387-1395$

97 Jiang H., Lu Z., Luo J.-Q., Wolfman A. and Foster D. A. (1995) Ras mediates the activation of phospholipase D by v-Src. J. Biol. Chem. 270: 6006-6009

98 Peso L. del, Lucas L., Esteve P. and Lacal J. C. (1997) Activation of phospholipase D by growth factors and oncogenes in murine fibroblast follow alternative but cross-talking pathways. Biochem. J. 322: 519-528

99 Peso L. del, Hernández R., Esteve P. and Lacal J. C. (1996) Activation of phospholipase $\mathrm{D}$ by Ras proteins is independent of protein kinase C. J. Cell. Biochem. 61: 599-608

100 Yamamoto H., Itoh F., Senota A., Adachi Y., Yoshimoto M., Endoh T. et al. (1995) Expression of matrix metalloproteinase matrilysin (MMP-7) was induced by activated Ki-ras via AP-1 activation in SW1417 colon cancer cells. J. Clin. Lab. Anal. 9: 297-301

101 Brunner G., Pohl J., Erkell L. J., Radler-Pohl A. and Schirrmacher V. (1989) Induction of urokinase activity and malignant phenotype in bladder carcinoma cells after transfection of activated Ha-ras oncogene. J. Cancer. Res. Clin. Oncol. 115: 139-144

102 Paciucci R., Tora M., Diaz V. M. and Real F. X. (1998) The plasminogen activator system in pancreas cancer: role of t-PA in the invasive potential in vitro. Oncogene 16: 625633

103 Silberman S., Janulis M. and Schultz R. M. (1997) Characterization of downstream Ras signals that induce alternative protease-dependent invasive phenotypes. J. Biol. Chem. 272: $5927-5935$
104 Zhang J. Y. and Schultz R. M. (1992) Fibroblasts transformed by different ras oncogenes show dissimilar patterns of protease gene expression and regulation. Cancer Res. 52: $6682-6689$

105 Su Z. Z., Austin V. N., Zimmer S. G. and Fisher P. B. (1993) Defining the critical gene expression changes associated with expression and suppression of the tumorigenic and metastatic phenotype in Ha-ras-transformed rat embryo fibroblast cell. Oncogene 8: 1211-1219

106 Chambers A. F., Colella R., Denhardt D. T. and Wilson S. M. (1992) Increased expression of cathepsins L and B and decreased activity of their inhibitors in metastatic, ras-transformed NIH 3T3 cells. Mol. Carcinogenesis 5: 238-245

107 Larcher F., Robles A. I., Duran H., Murillas R., Quintanilla M., Cano A. et al. (1996) Up-regulation of vascular endothelial growth factor/vascular permeability factor in mouse skin carcinogenesis correlates with malignant progression state and activated H-ras expression levels. Cancer Res. 56: 53915396

108 Steeg P. S., Bevilacqua G., Pozzatti R., Liotta L. A. and Sobel M. E. (1988) Altered expression of NM23, a gene associated with low tumor metastatic potential, during adenovirus 2 Ela inhibition of experimental metastasis. Cancer Res. 48: 6550-6554

109 Pozzati R., McCormick M., Thompson M. A. and Khoury G. (1998) The Ela gene of adenovirus type 2 reduces the metastatic potential of ras-transformed rat embryo cells. Mol. Cell. Biol. 8: 2984-2988

110 Garbisa S., Pozzati R., Muschel R. J., Saffiotti U., Ballin M., Goldfarb R. H. et al. (1987) Secretion of type IV collagenolytic protease and metastatic phenotype: induction by transfection with c-Ha-ras but not c-Ha-ras plus Ad2E1a. Cancer Res. 47: 1523-1528

111 Shibata K., Kikkawa F., Nawa A., Thant A. A., Naruse K., Mizutani S. et al. (1998) Both focal adhesion kinase and c-Ras are required for the enhanced matrix metalloproteinase 9 secretion by fibronectin in ovarian cancer cells. Cancer Res. 58: 900-903

112 Raff M. C. (1992) Social controls on cell survival and cell death. Nature 356: 397-400

113 Raff M. C., Barres B. A., Burne J. F., Coles H. S., Ishizaki Y. and Jacobson M. D. (1993) Programmed cell death and control of cell survival: lessons from nervous system. Science 262: $695-700$

114 Jacobson D., Weil M. and Raff M. (1997) Programmed cell death in animal development. Cell 88: $347-354$

115 Rudin C. M. and Thompson C. B. (1997) Apoptosis and disease: regulation and clinical relevance of programmed cell death. Annu. Rev. Med. 48: 267-281

116 Kerr J. F., Winterford C. M. and Harmon B. V. (1994) Apoptosis: its significance in cancer and cancer therapy. Cancer 73: 2013-2026

117 Tsujimoto Y., Finger L. R., Yunis J., Nowell P. C. and Croce C. M. (1984) Cloning of the chromosome breakpoint of neoplastic B cells with the $\mathrm{t}(14 ; 18)$ chromosome translocation. Science 226: 1097-1099

118 Cleary M. L., Smith S. D. and Sklar J. (1986) Cloning and structural analysis of cDNAs for bcl-2 and a hybrid bcl-2/ immunoglobulin transcript resulting from the $\mathrm{t}(14 ; 18)$ translocation. Cell 47: 19-28

119 Bakhshi A., Jensen J. P., Goldman P., Wright J. J., McBride O. W., Epstein A. L. et al. (1985) Cloning the chromosomal breakpoint of $\mathrm{t}(14 ; 18)$ human lymphomas: clustering around $\mathrm{JH}$ on chromosome 14 and near a transcriptional unit on 18 . Cell 41: 899-906

120 Ruoslahti E. and Reed J. C. (1994) Anchorage dependence, integrins, and apoptosis. Cell 77: 477-478

121 Frisch S. M. and Francis H. (1994) Disruption of epithelial cell-matrix interactions induces apoptosis. J. Cell Biol. 124: 619-626

122 Meredith J. E., Fazeli B. and Schwartz M. A. (1993) The extracellular matrix as a cell survival factor. Mol. Biol. Cell 4: $953-961$ 
123 Khwaja A., Rodriguez-Viciana P., Wennstrom S., Warne P. H. and Downward J. (1997) Matrix adhesion and Ras transformation both activate a phosphoinositide 3-OH kinase and protein kinase $\mathrm{B} / \mathrm{Akt}$ cellular survival pathway. EMBO J. 16: $2783-2793$

124 Evan G. and Littlewood T. (1998) A matter of life and cell death. Science 281: $1317-1322$

125 Evan G. I., Wyllie A. H., Gilbert C. S., Littlewood T. D., Land H., Brooks M. et al. (1992) Induction of apoptosis in fibroblasts by c-myc protein. Cell 69: 119-128

126 Shi Y., Glynn J. M., Guilbert L. J., Cotter T. G., Bissonnette R. P. and Green D. R. (1992) Role for c-myc in activation-induced apoptotic cell death in T cell hybridomas. Science 257: $212-214$

127 Kauffmann-Zeh A., Rodriguez-Viciana P., Ulrich E., Gilbert C., Coffer P., Downward J. et al. (1997) Suppression of c-Myc-induced apoptosis by Ras signalling through PI(3)K and PKB. Nature 385: 544-548
128 el-Deiry W.S. (1997) Role of oncogenes in resistance and killing by cancer therapeutic agents. Curr. Opin. Oncol. 9: 79-87

129 Jiménez B., Arends M., Esteve P., Perona R., Sánchez R., Ramón y Cajal S. et al. (1995) Induction of apoptosis in NIH $3 \mathrm{~T} 3$ cells by rho-p21, a GTPase protein of the ras superfamily. Oncogene 10: 811-816

130 Esteve P., del Peso L. and Lacal J. C. (1995) Induction of apoptosis by rho in NIH $3 \mathrm{~T} 3$ cells requires competence and progression signals: ceramides function as a progression factor for apoptosis. Oncogene 11: 2657-2665

131 Esteve P., Embade N., Perona R., Jiménez B., León J., Peso L. del et al. (1998) Rho-regulated signals induce apoptosis in vitro and in vivo by a p53-independent, but Bcl2-dependent pathway. Oncogene 17: 1855-1869

132 Lacal J. C. (1997) Regulation of proliferation and apoptosis by Ras and Rho GTPases through specific phospholipid-dependent signaling. FEBS Lett. 410: $73-77$

133 Fisher D. E. (1994) Apoptosis in cancer therapy: crossing the threshold. Cell 78: 539-542 